\title{
Smart Monitoring Berbasis Internet of Things (IoT) Suhu dan Kelembaban pada Kandang Ayam Broiler
}

\author{
(Smart Monitoring Based on Internet of Things (IoT) Temperature and Humidity in \\ Broiler Chicken Cage)
}

\author{
Yogi Isro Mukti, Fitria Rahmadayanti, Diti Tri Utami* \\ Program Studi Teknik Informatika, Sekolah Tinggi Teknologi Pagaralam \\ Jl. Masik Siagim No.75 Simpang Mbacang Kec.Demp Tengah Kota Pagar Alam \\ Email: yogie.isro.mukti@sttpagaralam.ac.id, ria.ria.rr77@gmail.com, detipga@gmail.com, sttp@sttpagaralam.ac.id
}

\section{*Penulis korespondensi}

\begin{abstract}
This study aims to design and build Internet of Things-based smart monitoring of temperature and humidity in broiler chicken coops in Talang Kemiling Pagar Alam that can facilitate and help breeders. This research is monitoring temperature and humidity which still uses the farmer's body itself as a temperature and humidity sensing tool so that farmers do not know what the actual temperature and humidity are in the chicken coop. Therefore, it is necessary to make a tool that can monitor temperature and humidity conditions in broiler chicken coops by utilizing the existing internet network using temperature and humidity sensors, namely DHT11, 1 channel relay for lamp control, and NODEMCU ESP8266 as a microcontroller that processes and transmits data from sensors. to the telegram server via the internet network, the telegram application on an android smartphone is used as an interface for monitoring temperature and humidity in broiler chicken coops remotely. This research uses the Rapid Application Development (RAD) system development method. The stages taken are Requirement Planning, Design Workshop, Build the System, and Implementation. To obtain data in this study, researchers conducted data collection techniques including observation, interviews, and literature study. The results expected from this study are the tools produced can help and facilitate breeders in raising broiler chickens.
\end{abstract}

Key words: Smart monitoring, Internet of Things, NODEMCU, Telegram, RAD

\section{PENDAHULUAN}

Seiring berkembangnya zaman saat ini di mana kemajuan teknologi yang kita ketahui bahwa perkembangannya dari waktu ke waktu semakin pesat. Saat ini, teknologi telah memberikan banyak kemudahan bagi manusia di dalam kehidupan sehari-hari dan juga dapat kita rasakan perkembangan teknologinya di mana alat elektronika yang kita punya dapat terhubung dengan mikrokontroler dan jaringan sehingga alat elektronik tersebut bisa dipantau dengan adanya sebuah sistem.

Teknologi yang telah dijelaskan yaitu Internet of Things (IoT) dan kini Internet of Things telah menjadi topik yang sangat hangat dibicarakan akhir-akhir ini. Internet of Things membuat perangkat alat elektronik dapat terhubung satu dengan yang lainnya [7]. Namun pemantauan suhu dan kelembaban pada kandang ayam saat ini masih banyak belum menggunakan penerapan dari Internet of Things [11] [2]. Dengan adanya penerapan dari IoT akan membuat peternak lebih mudah untuk mengetahui suhu dan kelembaban dan mencegah terjadinya penyakit pada ayam.

Dalam berternak ayam broiler, peternak mengalami beberapa kesulitan ataupun keluhan dalam berternak ayam broiler karena ayam broiler ini terkadang ada yang mati karena terkena penyakit bahkan peternak juga mengalami gagal panen ketika waktu panen telah tiba karena saat waktu panen bobot ayam belum mencapai target bobot ayam yang siap dipanen seperti di peternakan ayam broiler di Talang Kemiling Kecamatan Dempo Tengah, Kota Pagar Alam. Untuk melakukan pengecekan suhu dan kelembaban pada kandang ayam peternak masih manual menggunakan badannya sendiri sebagai peraba suhu dan kelembaban, sehingga peternak tidak tahu berapa suhu dan kelembaban yang sebenarnya yang ada pada kandang ayam tersebut. Suhu dan kelembaban pada kandang ayam merupakan salah satu elemen yang sangat penting dalam berternak ayam broiler karena suhu dan kelembaban pada kandang ayam harus selalu stabil atau optimal. Ketika suhu pada kandang ayam terlalu panas, maka ayam akan mengalami stres sehingga ayam akan lebih banyak minum daripada makan dan ketika suhu pada kandang ayam terlalu dingin, maka pertumbuhan pada ayam broiler ini akan terhambat dan ayam bisa mati [5]. Dengan adanya perkembangan teknologi saat ini dapat membantu dan mempermudah para peternak dalam melakukan pemantauan (monitoring) suhu dan kelembaban melalui smartphone.

Ayam pedaging (broiler) ini memiliki daya produktivitas yang sangat tinggi dalam memproduksi daging [9] [10]. 
Berdasarkan permasalahan yang telah dijelaskan di atas maka dibutuhkan smart monitoring untuk memantau suhu dan kelembaban pada kandang ayam broiler untuk menjadikan proses berternak yang mengikuti perkembangan teknologi saat ini, karena smart monitoring ini dapat membantu dan mempermudah pekerjaan peternak agar kandang ayam selalu stabil suhu dan kelembabannya agar terhindar dari penyakit pada ayam. Penerapan IoT pada smart monitoring ini peternak nantinya akan lebih efektif dalam melakukan pemantauan karena untuk mengetahui suhu dan kelembaban pada kandang ayam akan menggunakan smartphone untuk melihat notifikasi yang dikirim dari alat [5] [3] .

\section{TINJAUAN PUSTAKA}

Penelitian terkait yang mengenai sistem monitoring peternakan ayam broiler berbasis internet of things pada penelitian [5] memiliki persamaan dengan yang peneliti buat yaitu menggunakan sensor DHT11 sebagai alat pemantau suhu dan kelembaban. Sedangkan untuk perbedaan pada penelitian [5] menggunakan Arduino Mega 2560 sebagai mikrokontoler karena sistem yang dibuat banyak menggunakan pin input dan output.

Pada tahun 2020 dilakukan penelitian oleh (Saputra \& Siswanto, 2020) mengenai "Prototype Sistem Monitoring Suhu Dan Kelembaban Pada Kandang Ayam Broiler Berbasis Internet Of Things" dimana pada penelitian [6] ini memiliki persamaan yaitu menggunakan relay 4 channel sebagai saklar untuk on/off dari komponen alat yang digunakan. Sedangkan untuk perbedaannya peneliti [6] menggunakan 2 kipas sebagai pendingin pada kandang ayam broiler.

Pada tahun 2018 penelitian yang dilakukan oleh [4] dengan judul "Rancangan Bangun Sistem Kontrol Otomatis Pengatur Suhu Dan Kelembapan Kandang Ayam Broiler Menggunanakan Arduino" pada penelitiannya memiliki persamaan yaitu menggunakan aplikasi blynk sebagai pemantauan atau monitoring suhu dan kelembaban pada kandang ayam. Sedangkan untuk perbedaannya dengan yang peneliti buat yaitu bahwa penelitian yang dilakukan oleh [4] menggunakan Ethernet Shield W5100 sebagai modul wi-fi karena penelitiannya menggunakan Arduino Mega 2560.

Pada tahun 2019 penelitian yang dilakukan oleh [1] tentang "Perancangan Sistem Kontrol Suhu dan Kelembaban Ruangan pada Budidaya Jamur Tiram Berbasis Internet of Things" pada penelitian ini untuk persamaannya menggunakan modul wi-fi ESP8266 sebagai mikrokontroler dan sebagai modul wi-fi agar alat yang dibuat dapat terhubung dengan jaringan internet. Selain itu projek yang dibuat dengan menggunakan ESP8266 ini untuk pemantauan suhu dan kelembabannya dapat dilakukan dari jarak jauh. Sedangkan perbedaan penelitian ini dengan penelitian [1] bahwa alat yang dibuatya untuk ruangan budidaya jamur.

Pada tahun 2020 penelitian yang dilakukan oleh [8] tentang "Perancangan dan Pembuatan Sistem Monitoring Suhu Ayam, Suhu dan Kelembaban Kandang untuk
Meningkatkan Produktifitas Ayam Broiler" memiliki persamaan yaitu untuk penghangat ayam di dalam kandang menggunakan lampu pijar di mana lampu pijar ini merupakan lampu yang digunakan untuk penghangat ayam di dalam kandang karena memilik filament yang bisa menghantarkan panas. Adapun perbedaan antara penelitian ini dengan penelitian [8] bahwa dalam penelitiannya menggunakan 2 buah sensor suhu dan kelembaban yaitu sensor DHT11 dan FAR IR MLX90640.

Dari penelitian yang telah dilakukan di atas, proses pemantauan suhu dan kelembaban sudah menggunakan Internet of Things dan sudah bisa diimplementasikan dengan baik dan para peneliti telah berhasil membangun sistem pemantauan suhu dan kelembaban yang dapat digunakan oleh peternak untuk membantu dan mempermudah pekerjaan dalam memantau suhu dan kelembaban. Pada sensor membaca nilai suhu dan kelembaban maka mikrokontroler akan menampilkan nilai baca dari sensor melalui aplikasi pada smartphone yaitu aplikasi blynk.

\section{Metode PERANCANGAN}

\section{A. Alur Penelitian}

Tahapan pertama yang dilakukan pada penelitian ini yaitu melakukan analisa kebutuhan yang berarti sebuah tahapan untuk menganalisis atau mengidentifikasi kebutuhan dan masalah yang dihadapi untuk menentukan tujuan, batasan-batasan sistem, kendala dan pemecahan masalah. Analis digunakan untuk mengetahui perilaku sistem dan juga untuk mengetahui aktivitas apa saja yang ada dalam sistem tersebut. Langkah selanjutnya yaitu perancangan hardware (perangkat keras) kemudian dilanjutkan dengan perancangan software (perangkat lunak), di mana perancangan hardaware (perangkat keras) merupakan sebuah perancangan alat perangkat dari internet of things yang akan dibuat sedangkan perancangan hardware (perangkat lunak) merupakan sebuah perancangan yang berkaitan dengan pengiriman data dari sensor ke aplikasi yang dipakai sebagai monitoring. Setelah melakukan perancangan hardware (perangkat keras) dan perancangan software (perangkat lunak) maka tahap selanjutnya yaitu tahap implementasi yang merupakan tahapan di mana tahapan sistem yang dikembangkan sudah siap untuk di implementasikan (coding) ke dalam bentuk yang dimengerti oleh mesin yang terwujud dalam bentuk program atau unit program. Tahap implementasi sistem merupakan tahap meletakkan sistem supaya siap dioperasikan. Langkah selanjutnya atau langkah terakhir yaitu pengujian yang merupakan tahapan di mana sistem yang telah dibuat siap untuk diujikan, jika pengujian yang dilakukan tidak sesuai dengan yang kebutuhan sistem maka akan kembali lagi ke tahapan perancangan dan apabila pengujian yang dilakukan berhasil maka sistem atau program yang dibuat siap digunakan. Di bawah ini merupakan alur atau tahapan dari penelitian dapat dilihat pada Gambar 1. 


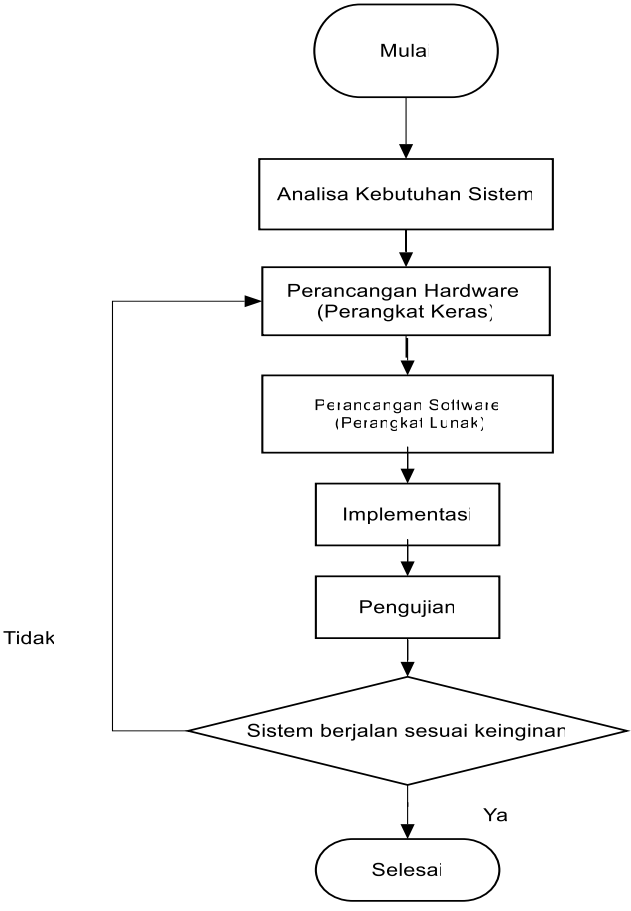

Gambar 1. Alur atau Tahapan Penelitian

\section{B. Perancangan Perangkat Keras (Haardware)}

Pada tahapan perancangan perangkat keras (hardware) ini akan dilakukan perancangan dari blok diagram sistem dan rangkaian dari smart monitoring berbasis internet of things suhu dan kelembaban pada kandang ayam broiler.

\section{B.1. Rancangan Arsitektur Sistem}

Gambar dari arsitektur blok diagram sistem yang akan dibuat dapat dilihat pada Gambar 2.
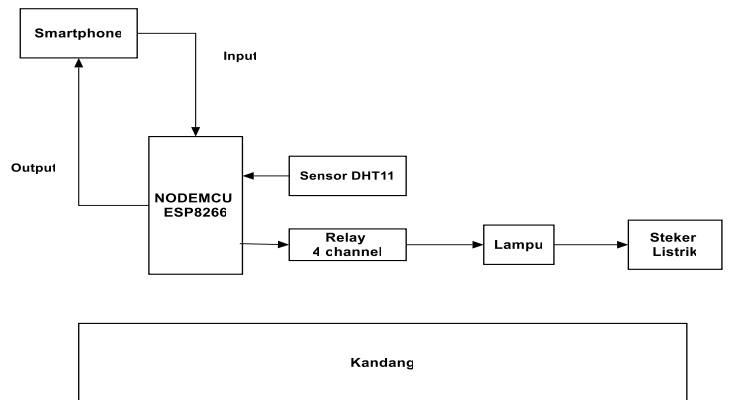

Gambar 2. Arsitektur Blok Diagram Sistem

Pada Gambar 2 merupakan gambar alur dari blok diagram sistem. Berikut penjelasan dari blok diagram sistem yang terdapat pada gambar 2 .

1. Smartphone digunakan sebagai monitoring suhu dan kelembaban pada kandang ayam broiler.

2. Nodemcu ESP8266 bertindak sebagai otak dari sistem yang akan dibuat di mana bahwa sensor dht11 dan relay 4 channel dihubungkan ke nodemcu esp8266. Ketika sensor dht11 membaca suhu dan kelembaban maka data tersebut akan diolah pada mikrokontroler yang ada padanodemcu esp 8266 kemudian data dapat ditampilkan pada aplikasi yang ada pada smartphone, kemudian on/off pada relay akan bekerja sesuai dengan program yang telah dibuat.

Adapun rancangan dari sistem adalah seperti gambar pada Gambar 3.

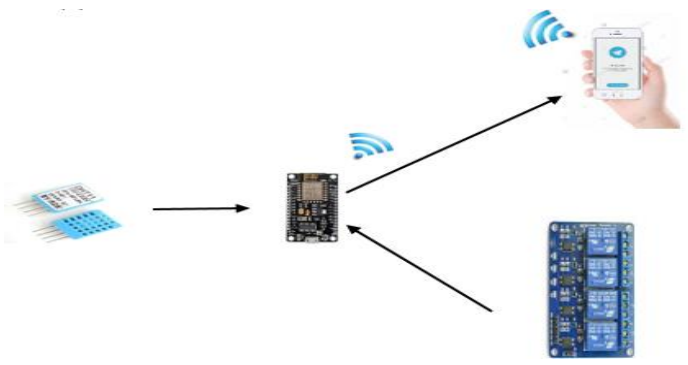

Gambar 3. Rancangan Arsitektur Sistem

Berikut ini merupakan penjelasan dari setiap komponen yang terdapat pada gambar 3 :

1. Aplikasi Blynk yang ada pada smartphone dihubungkan dengan nodemcu esp 8266 agar proses monitoring dapat dilakukan dengan smartphone dan juga bisa dilakukan dengan jarak jauh asalkan sistem yang dibuat terhubungan dengan jaringan internet.

2. Sensor dht11 dihubungkan dengan nodemcu esp8266 agar saat sensor membaca suhu dan kelembaban maka pembacaan dari sensor dht1l akan diproses pada mikrokontroler yang ada pada nodemcu esp 822 kemudian data ditampilkan pad aplikasi blynk yang ada pada smartphone.

3. Relay 4 channel dihubungkan dengan nodemcu esp 8266 yang akan memutuskan dan menghidupkan arus aliran listrik pada lampu.

\section{B.2. Rangkaian Elektronika Sistem}

Rangkaian elektronika sistem yang akan dibangun dapat dilihat pada Gambar 4.

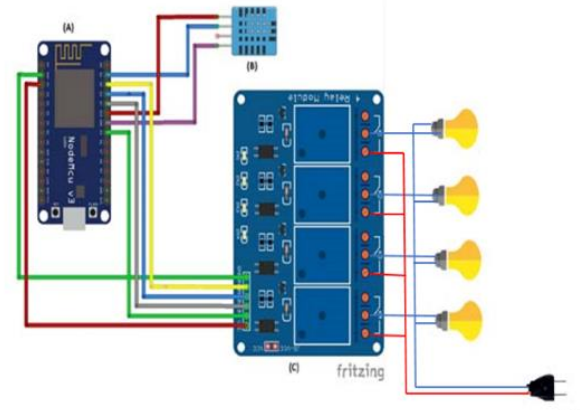

Gambar 4. Rangkaian Elektronika Sistem

Dari sebuah rangkaian yang ada pada Gambar 4 terlihat bahwa ada 2 input an yang terhubung dengan mikrokontroler yang ada pada nodemcu esp 8266 yaitu sensor dht11 dan relay 4 cahnnel. 


\section{Perancangan Perangkat Lunak}

Perancangan perangkat lunak pada tahapan ini adalah untuk merancang sistem smart monitoring suhu dan kelembaban dan juga pada tahapan perancangan perangkat lunak ini akan melakuan pemrograman pada mikrokontroler yang ada pada nodemcu esp 8266 dan akan merancang bagaimana terhubungnya dari perangkat lunak (software) dengan perangkat keras (hardware).

\section{C.1 Use Case Diagram}

Use case pada penelitian ini peternak akan membuka aplikasi pada smartphone yaitu aplikasi blynk, setelah membuka aplikasi blynk peternak mengecek suhu dan kelembaban maka aplikasi blynk langsung menampilkan nilai suhu dan kelembaban, apabila suhu pada kandang ayam terlalu dingin maka lampu akan otomatis hidup dan apabila suhu terlalu panas maka aplikasi akan menampilkan sebuah notifikasi. Adapun rancangan use case yang akan dibangun pada penelitian ini dapat dilihat pada Gambar 5.

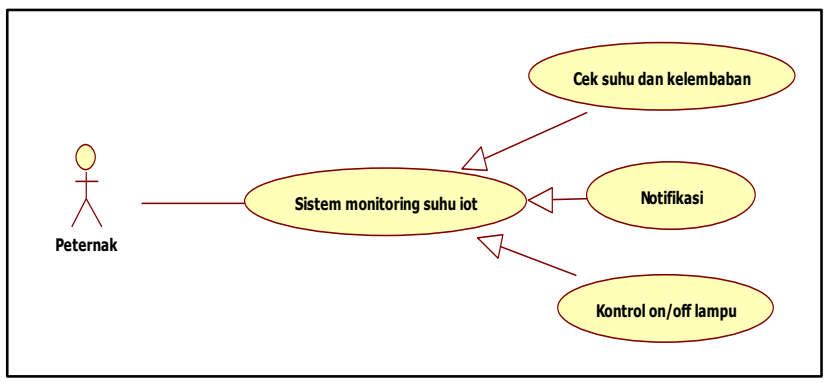

Gambar 5. Use Case Diagram

\section{C.2 Program Pada Mikrokontroler}

Pada tahapan ini akan akan dilakukan sebuah pemrograman mikrokontroler yang terdapat pada esp8266 untuk melihat pembacaan data yang dilakkan oleh sensor dht11 dan untuk sebagai on/off lampu secara otomatis dan juga pada mikrokontroler akan diprogram agar sistem atau alat yang akan dibuat dapat terhubung dengan jaringan internet dan bisa terhubung antara sensor dht11 dengan aplikasi blynk ketika sensor sudah membaca nilai suhu dan kelembaban. Pemrograman pada mikrokontroler dilakukan dengan menggunakan sebuah aplikasi yaiu Arduino IDE dan Bahasa pemrograman yang digunakan pada aplikasi ini adalah Bahasa pemrograman $\mathrm{C}++$.

\section{C.3 Arsitektur Komunikasi Data}

Arsitektur komunikasi data ini menggambarkan komunikasi data pada aplikasi blynk yang ada pada smartphone dimana awal komunikasi data ini dimulai dari ketika sensor dht11 melakukan pembacaan suhu dan kelembaban kemudisn data diolah pada mikrokontroler dan selanjutnya data akan ditampilkan pada blynk dan ketika suhu kurang dari suhu yang ditentukan maka lampu akan secara otomatis mati dan jika pembacaan suhu lebih dari yang telah ditentukan maka lampu akan secara otomatis mati. Untuk gambaran proses komunikasi data pada blynk bisa dilihat pada Gambar 6 .

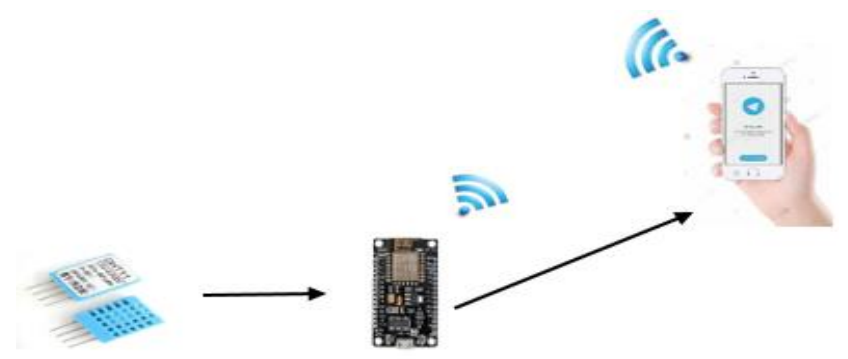

Gambar 6. Arsitektur Komunikasi Data

\section{Implementasi}

Pada tahapan implementasi pada penelitian ini dilakukan tiga tahapan atau proses yaitu sebagai berikut :

1. Melakukan perangkaian perangkat keras (hardware) yang dipakai yaitu mikrokontroler nocemcu esp8266, sensor dht11, relay 4 channel dan perangkaian lampu yang perangkaiannya dibuat menjadi sebuah rangkaian sistem perangkat keras (hardware) dengan menyesuaikan rancangan perangkat keras sistem yang dibuat.

2. Melakukan perancangan smart monitoring suhu dan kelembaban pada aplikasi blynk.

3. Melakukan pembuatan komunikasi pemprosesan data dari blynk dengan alat yang yang telah dirangkai sebelumnya.

\section{E. Pengujian dan Evaluasi Sistem}

Pada tahapan pengujian dan evaluasi sistem merupakan pengujian yang akan dilakukan terhadap perangkat keras (hardware) dan perangkat lunak (software). Pengujian perangkat keras (hardware) yaitu melakukan pengujian pada alat atau perangkat keras (hardware) yang digunakan seperti nodemcu esp8266, relay 4 channel dan sensor dht11. Sedangkan pengujian perangkat lunak (software) yaitu melakukan pengujian pada perangkat lunak (software) yaitu pada aplikasi blynk.

\section{HASIL DAN PEMBAHASAN}

Pada tahapan ini yang akan dibahas yaitu hasil dari penelitian yang telah dilakukan. Realisasi yang telah dibuat sesuai dengan sebuah rancangan yang telah dibuat pada sebelumnya, pada tahapan ini juga akan membahas tentang hasil dari pengujian terhadap sistem atau alat yang dibuat dan serta evaluasi terhadap sistem atau alat yang sudah berjalan.

\section{A. Hasil Rangkaian Perangkat Keras}

Hasil rangkaian perangkat keras fokus pada rancangan perangkat keras atau hardware yang telah dilakukan pada tahapan sebelumnya. Pada perancangan penyusunan perangkat keras ini semua perangkat keras yang digunakan dibuat dalam satu rancangan. Untuk hasil rangkaian dari perangkat keras yang dibuat untuk rangkaiannya dapat dilihat pada Gambar 7 sampai 10. 


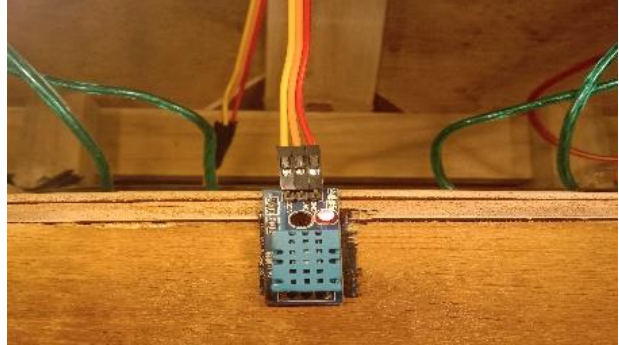

Gambar 7. Hasil Rangkaian Sensor Dht11

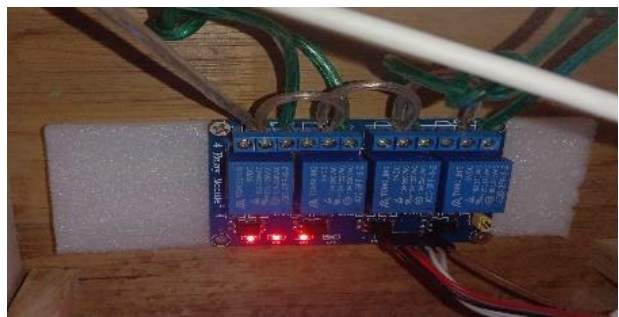

Gambar 8. Hasil Rangkaian Relay 4 Channel

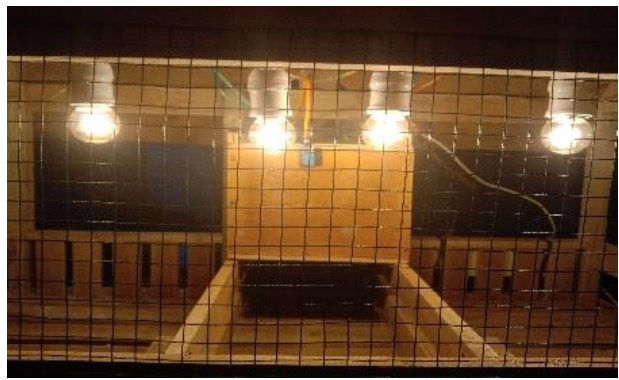

Gambar 9. Hasil Rangkaian Lampu

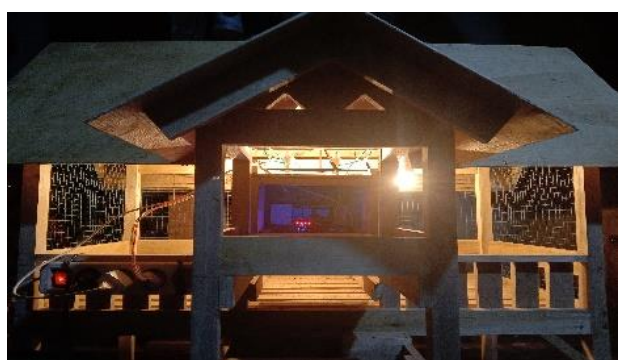

Gambar 10. Hasil Rangkaian Keseluruhan Alat

Pada gambar hasil keseluruhan alat bahwa ada 4 perangkat keras yang digunakan pada Gambar 10 yaitu nodemcu esp8266, sensor dht11, relay 4 channel dan lampu, keeampat perangkat keras yang digunakan memiliki fungsi masing-masing sebagai berikut untuk penjelasannya :

1. Nodemcu esp8266 berfungsi sebagai mikrokontroler dimana pada mikrokontroler ini sudah memiliki modul wi-fi.

2. Sensor dht1l berfungsi untuk melakukan pembacaan suhu dan kelembaban pada kandang ayam.

3. Relay 4 channel berfungsi untuk memutuskan menghidupkan arus dari aliran listrik pada lampu.

4. Lampu berfungsi untuk sumber penghangat ayam di dalam kandang.

\section{B. Hasil Dashboard Perangkat Lunak}

Hasil rangkaian perangkat lunak fokus pada rancangan perangkat lunakatau softwareyang telah dilakukan pada tahapan sebelumnya. Untuk hasil tampilan dari perangkat lunak yang dibuat untuk dapat dilihat pada Gambar 11 .

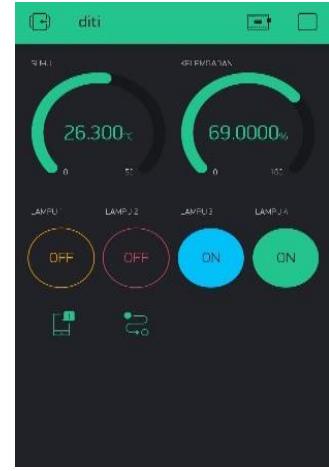

Gambar 11. Hasil Dashboard Perangkat Lunak

\section{Hasil Pemrograman Pada Mikrokontroler}

Hasil dari pemrogramanan pada mikrokontroler yang dibuat dengan menggunakan aplikasi Arduino IDE di mana untuk bahasa pemrogramannya menggunakan bahasa $\mathrm{C}$. Berikut ini penjelasan dari program atau source kode yang ada pada mikrokontroler:

\#define BLYNK PRINT Serial

\#include <ESPBי266WiFi.h>

\#include <BlynkSimpleEsp8266.h>

\#include <DHT.h>

Script kode program di atas adalah perintah untuk memasukkan library aplikasi yang akan digunakan dalam program mikrokontroler.

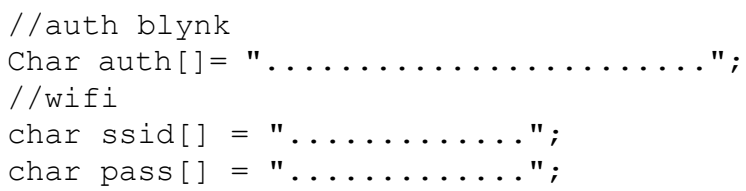

Script kode program di atas adalah bagian pengisian token yang dikirim ke alamat email kita dan untuk nama wifi dan password silahkan diisi juga dengan wifi yang akan digunakan.

Script kode program di atas adalah untuk pin data yang digunakan pada perangkat keras sensor dht11 dan relay 4 channel. 


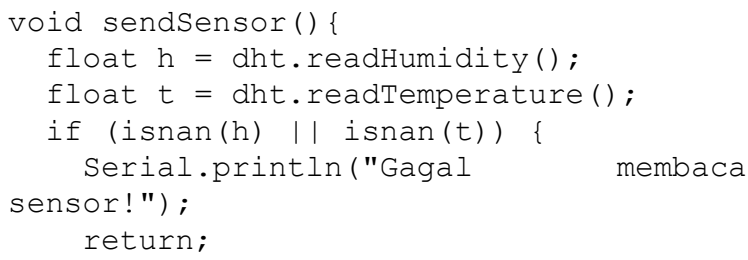

Script kode program di atas adalah untuk perintah pembacaan suhu dan kelembaban yang dilakukan oleh sensor $d h t 11$.

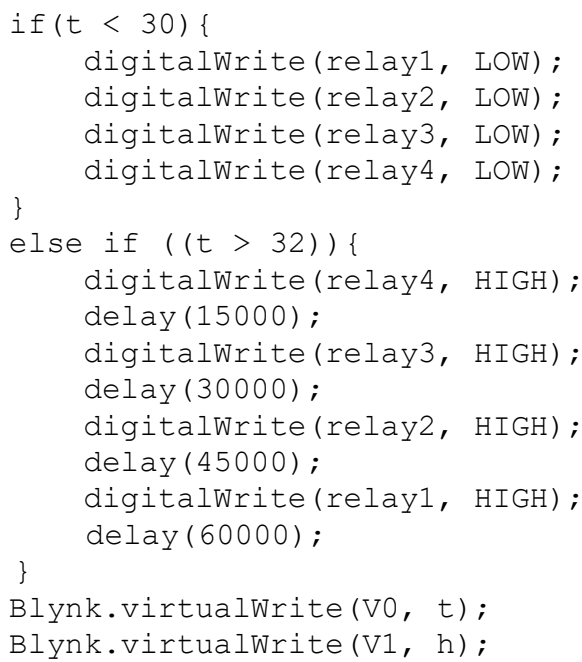

Script kode program di atas adalah bagian fungsi atau kerja dari relay di mana relay akan bekerja sesuai dengan perintah yang ditanamkan pada program sesuai dengan suhu yang telah ditentukan.

\section{Pengujian Hasil Uji Fungsional}

Pengujian hasil uji fungsional yang dilakukan pada tahapan ini dilakukan untuk menguji dari komponen alat atau sistem yang digunakan sudah berjalan sesuai dengan yang diharapkan.

\section{D.1 Pengujian Sensor DHT11}

Pengujian pada sensor dhtll adalah untuk menguji apakah sensor dapat membaca suhu dan kelembaban. Berdasarkan hasil pengujian pada sensor $d h t 11$ bahwa hasil pengujian rata-rata error dari pengukuran suhu mempunyai tingkat error sebesar $1,18 \%$. Hasil perhitungan error (\%) dan rata-rata error adalah $0,42(\%)$ seperti yang terlihat pada Tabel I. Sedangkan hasil pengujian rata-rata error dari pengukuran kelembaban mempunyai tingkat error sebesar $7,46 \%$. Hasil perhitungan error $(\%)$ dan rata-rata error $0,74(\%)$ seperti yang terlihat pada Tabel II.

\section{D.2. Pengujian Relay 4 Channel}

Pengujian relay dilakukan untuk menguji performa dari kelayakan relay sehingga sesuai dengan apa yang diharapkan, pemasangan kabel untuk lampu dihubungkan ke pin $N O$ (Normaly Open) pada relay agar kondisi posisi awal lampu terbuka atau arus dari lsitrik terputus. Hasil pengujian seperti yang terlihat pada Tabel III.

TABEL I. PENGUJIAN SUHU

\begin{tabular}{|c|c|c|c|c|c|}
\hline No & Waktu & $\begin{array}{c}\text { Alat } \\
\text { Ukur } \\
\text { Thermometer } \\
\left({ }^{\circ} \mathbf{C}\right)\end{array}$ & $\begin{array}{c}\text { Sensor } \\
\text { DHT11 } \\
\left({ }^{\circ} \mathbf{C}\right)\end{array}$ & $\begin{array}{c}\text { Selisih } \\
\left({ }^{\circ} \mathbf{C}\right)\end{array}$ & $\begin{array}{c}\text { Error } \\
(\boldsymbol{\%})\end{array}$ \\
\hline 1. & Detik ke-5 & 25,6 & 25,3 & 0,3 & 1,18 \\
\hline 2. & Detik ke-10 & 25,4 & 25,3 & 0,1 & 0,39 \\
\hline 3. & Detik ke-15 & 25,5 & 25,4 & 0,1 & 0,39 \\
\hline 4. & Detik ke-25 & 26 & 26 & 0 & 0 \\
\hline 5. & Detik ke-30 & 26,1 & 26 & 0,1 & 0,38 \\
\hline 6. & Detik ke-40 & 26,8 & 26,8 & 0 & 0 \\
\hline 7. & Detik ke-45 & 27 & 26,9 & 0,1 & 0,37 \\
\hline 8. & Detik ke-50 & 26,8 & 26,5 & 0,3 & 1,13 \\
\hline 9. & Detik ke-55 & 26,8 & 26,7 & 0,3 & 0,37 \\
\hline 10. & Detik ke-60 & 27 & 27 & 0 & 0 \\
\hline & & & \multicolumn{2}{c|}{ Rata-rata } & $\mathbf{0 , 4 2}$ \\
\hline
\end{tabular}

TABEL II. Pengujian Kelembaban

\begin{tabular}{|c|c|c|c|c|c|}
\hline No & Waktu & $\begin{array}{c}\text { Alat Ukur } \\
\text { Thermometer } \\
(\%)\end{array}$ & $\begin{array}{c}\text { Sensor } \\
\text { DHT11 } \\
(\%) \\
\end{array}$ & $\begin{array}{c}\text { Selisih } \\
(\%)\end{array}$ & $\begin{array}{c}\text { Error } \\
(\%)\end{array}$ \\
\hline 1. & Detik ke-5 & 67 & 65 & 2 & 3,07 \\
\hline 2. & Detik ke-10 & 64 & 63 & 1 & 1,58 \\
\hline 3. & Detik ke-15 & 62 & 61,9 & 0,1 & 0,16 \\
\hline 4. & Detik ke-25 & 64 & 63 & 1 & 1,58 \\
\hline 5. & Detik ke-30 & 64,1 & 63,8 & 0,3 & 0,47 \\
\hline 6. & Detik ke-40 & 65 & 65 & 0 & 0 \\
\hline 7. & Detik ke-45 & 65,5 & 65,4 & 0,1 & 0,15 \\
\hline 8. & Detik ke-50 & 65,2 & 65,2 & 0 & 0 \\
\hline 9. & Detik ke-55 & 64,9 & 64,7 & 0,2 & 0,3 \\
\hline 10. & Detik ke-60 & 64,8 & 64,7 & 0,1 & 0,15 \\
\hline \multicolumn{5}{|c|}{ Rata-rata } & 0,74 \\
\hline
\end{tabular}

TABEL III. PENGUJIAN RELAY

\begin{tabular}{|c|c|c|l|c|}
\hline No & \multirow{2}{*}{ Relay } & $\begin{array}{c}\text { Kondisi } \\
\text { Relay }\end{array}$ & \multicolumn{1}{|c|}{ Keterangan } & Pengujian \\
\hline 1 & Relay 1 & OFF & $\begin{array}{l}\text { Relay 1 memutus aliran } \\
\text { listrik ke lampu }\end{array}$ & Benar \\
\cline { 3 - 5 } & ON & $\begin{array}{l}\text { Relay 1 } \\
\text { menghubungkan aliran } \\
\text { listrik ke lampu }\end{array}$ & Benar \\
\hline 2 & Relay 2 & OFF & $\begin{array}{l}\text { Relay 2 memutus aliran } \\
\text { listrik ke lampu }\end{array}$ & Benar \\
\cline { 3 - 5 } & ON & $\begin{array}{l}\text { Relay 2 } \\
\text { menghubungkan aliran } \\
\text { listrik ke lampu }\end{array}$ & Benar \\
\hline 3 & Relay 3 & OFF & $\begin{array}{l}\text { Relay 3 memutus aliran } \\
\text { listrik ke lampu }\end{array}$ & Benar \\
\cline { 3 - 5 } & ON & $\begin{array}{l}\text { Relay 3 } \\
\text { menghubungkan aliran } \\
\text { listrik ke lampu }\end{array}$ & Benar \\
\hline 4 & Relay 4 & OFF & $\begin{array}{l}\text { Relay 4 memutus aliran } \\
\text { listrik ke lampu }\end{array}$ & Benar \\
\cline { 3 - 5 } & ON & $\begin{array}{l}\text { Relay 4 } \\
\text { menghubungkan aliran } \\
\text { listrik ke lampu }\end{array}$ & Benar \\
\hline \multirow{2}{*}{} & & & \\
\hline & & & \\
\hline
\end{tabular}




\section{D.3. Pengujian Respon Pada Aplikasi Blynk}

Pengujian ini dilakukan untuk mengetahui respon aplikasi blynk pada alat dan juga untuk mengetahui berapa selisih waktu antara aplikasi blynk dengan alat. Hasil pengujian respon aplikasi blynk dapat dilihat pada Tabel IV.

\section{TABEL IV. RESPON PADA APLIKASI BLYNK}

\begin{tabular}{|c|c|c|c|}
\hline No & $\begin{array}{c}\text { Waktu } \\
\text { Mengirim } \\
\text { Data }\end{array}$ & $\begin{array}{c}\text { Waktu } \\
\text { Menerima } \\
\text { Data }\end{array}$ & $\begin{array}{c}\text { Selisih Waktu } \\
\text { (S) }\end{array}$ \\
\hline 1 & $20: 05: 00$ & $20: 05: 2$ & $2 \mathrm{~S}$ \\
\hline 2 & $20: 05: 20$ & $20: 05: 22$ & $2 \mathrm{~S}$ \\
\hline 3 & $20: 05: 35$ & $20: 05: 36$ & $1 \mathrm{~S}$ \\
\hline 4 & $20: 05: 49$ & $20: 05: 51$ & $2 \mathrm{~S}$ \\
\hline 5 & $20: 06: 10$ & $20: 06: 12$ & $2 \mathrm{~S}$ \\
\hline 6 & $20: 06: 23$ & $20: 06: 24$ & $1 \mathrm{~S}$ \\
\hline 7 & $20: 06: 38$ & $20: 06: 39$ & $1 \mathrm{~S}$ \\
\hline 8 & $20: 07: 03$ & $20: 07: 05$ & $2 \mathrm{~S}$ \\
\hline 9 & $20: 07: 15$ & $20: 07: 17$ & $2 \mathrm{~S}$ \\
\hline 10 & $20: 07: 28$ & $20: 07: 31$ & $3 \mathrm{~S}$ \\
\hline \multicolumn{3}{|c|}{ Rata-rata } & $\mathbf{1 , 8} \mathbf{S}$ \\
\hline
\end{tabular}

\section{D.4. Pengujian Delay On/Off Lampu}

Pada Tabel V menunjukkan nilai rata-rata delay waktu ketika menekan tombol ON pada aplikasi blynk dan waktu respon ketika lampu hidup. Sedangkan, pada Tabel VI menunjukkan nilai rata-rata delay waktu ketika menekan tombol OFF pada aplikasi blynk dan waktu respon ketika lampu mati.

TABEL V. DELAY ON LAMPU

\begin{tabular}{|c|c|c|c|}
\hline No & Lampu & Keadaan & Delay (s) \\
\hline 1 & Lampu 1 & ON & 0,6 \\
\hline 2 & Lampu 2 & ON & 0,3 \\
\hline 3 & Lampu 3 & ON & 0,2 \\
\hline 4 & Lampu 4 & ON & 0,2 \\
\hline \multicolumn{3}{|c|}{ Rata-rata } & $\mathbf{0 , 3 2}$ \\
\hline
\end{tabular}

TABEL VI. DELAY OFF LAMPU

\begin{tabular}{|c|c|c|c|}
\hline No & Beban & keadaan & Delay (s) \\
\hline 1 & Lampu 1 & OFF & 0,2 \\
\hline 2 & Lampu 2 & OFF & 0,2 \\
\hline 3 & Lampu 3 & OFF & 0,1 \\
\hline 4 & Lampu 4 & OFF & 0,2 \\
\hline \multicolumn{3}{|c|}{ Rata-rata } & $\mathbf{0 , 2 3}$ \\
\hline
\end{tabular}

\section{D.5. Tampilan Notifikasi}

Notifikasi pada aplikasi blynk akan ditampilkan ketika suhu lebih dari $32^{\circ} \mathrm{C}$ atau telah melebihi batas suhu kebutuhan suhu yang dibutuhkan ayam. Gambar 12 merupakan tampilan notifikasi pada aplikasi blynk yang ditampilkan pada smartphone.

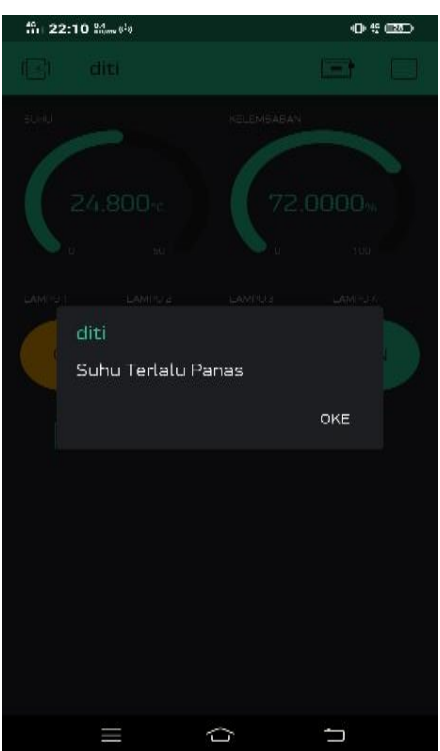

Gambar 12. Tampilan Notifikasi

Hasil Dan KesimpUlan

A. Kesimpulan

Dari hasil pengujian yang telah dilakukan pada prototype smart monitoring berbasis internet of things suhu dan kelembaban memiliki beberapa kesimpulan yaitu sebagai berikut :

1. Prototype smart monitoring berbasis internet of things suhu dan kelembaban menggunakan nodemcu esp8266 sebagai mikrokontroller, sensor dht11, dan relay.

2. Proses pemantauan suhu dan kelembaban dapat dilakukan dengan jarak yaitu dengan aplikasi blynk dan bantuan jaringan internet.

3. Dari hasil pengujian yang telah dilakukan pada smart monitoring berbasis iot suhu dan kelembaban telah berhasil dilakukan dengan ratarata tingkat kesalahan atau error pada suhu yaitu $0,88 \%$, kelembaban $0,42 \%$, dengan rata-rata delay $O N$ lampu sebesar 0,32 sekon dan delay OFF sebesar 0,23 sekon..

\section{B. Saran}

Adapun dalam penelitian ini pengembangan yang dapat dilakukan oleh peneliti lain adalah sebagai berikut :

1. Alat dapat diterapkan pada seluruh umur ayam dari bibit ayam sampai ke ayam siap panen.

2. Ketika listrik padam maka prototype tidak berfungsi karena prototype memperoleh daya melalui charger handphone yang tersambung ke aliran listrik secara langsung.

3. Untuk penelitian selanjutnya bisa membuat lampu on/off secara otomatis berdasarkan semua umur ayam. 


\section{DAFTAR PUSTAKA}

[1] Devi, N. S., Erwanto, D., \& Utomo, Y. B. (2019). Perancangan Sistem Kontrol Suhu Dan Kelembaban Ruangan Pada Budidaya Jamur Tiram Berbasis Internet Of Things. 6223(2), 104-113.

[2] Fathurrahmani, Wiwik, K., Khairul, A. H., \& Arif, S. (2019). Penerapan Sistem Tertanam Untuk Monitoring Kandang Ayam Broiler. 19(1), 53-61.

[3] Hendra, A., \& Hadis, M. S. (2019). Sistem Kontrol Suhu Ideal Kandang Ayam Broiler Berbasis Teknologi Internet Of Things ( Iot ) Ideal Temperature Control System For Broiler Chicken Coops Based On Internet Of Things ( Iot ) Technology. 79-82.

[4] Mansyur, F. M. (2018). Rancangan Bangun Sistem Kontrol Otomatis Pengatur Suhu Dan Kelembapan Kandang Ayam Broiler Menggunanakan Arduino. 0881, 28-38.

[5] Masriwilaga, A. A., Al-Hadi, T. A. J. M., Subagja, A., \& Septiana, S. (2018). Sistem Monitoring Peternakan Ayam Broiler Berbasis Internet Of Things (APRIL 2018, Vol. 7, Issue Https://Doi.Org/10.34010/Telekontran.V7i1.1641

[6] Saputra, J. S., \& Siswanto. (2020). Prototype Sistem Monitoring Suhu Dan Kelembaban Pada Kandang Ayam Broiler Berbasis Internet Of Things (April 2018, Vol. 7, Issue 1).
[7] Sigit, W., Setiawardhana, Saraswati, A. D., \& Eko, S. (2019). Aplikasi Internet Of Things (Iot) Dengan ARDUINO Dan ANDROID "Membangun Smartt Home Dan Smart Robot Berbasis Arduino Dan Android."

[8] Turesna, G., Andriana, A., Abdul Rahman, S., \& Syarip, M. R. N. (2020). Perancangan Dan Pembuatan Sistem Monitoring Suhu Ayam, Suhu Dan Kelembaban Kandang Untuk Meningkatkan Produktifitas Ayam Broiler. Jurnal TIARSIE, $\quad 17(1)$ Https://Doi.Org/10.32816/Tiarsie.V17i1.67

[9] Umam, M. K., Prayogi, H. S., \& Nurgiartiningsih, V. M. A. (2018). The Performance Of Broiler Rearing In System Stage Floor And Double Floor (APRIL 2018, Vol. 24, Issues 0852-3581).

[10] Wati, A. K., Indarto, E., \& Dono, N. D. (2018). Performan Ayam Broiler Dengan Penambahan Tepung Daun Calliandra Calothyrsus Dalam Pakan Performance Of Broiler Chickens With Addition Of Calliandra Calothyrsus Leaf Meal In Feed. 16(September), 74-79.

[11] Wijanarko, D., \& Hasanah, S. (2018). Monitoring Suhu Dan Kelembaban Menggunakan Sms Gateway Pada Proses Fermentasi Tempe Secara Otomatis Berbasis Mikrokontroler (APRIL 2018, Vol. 4, Issue 1). Https://Doi.Org/10.33795/Jip.V4i1.144 